\title{
Purely mechanically driven door-controlled disinfection device for automatic COVID-19
}

\author{
Hajar Saikouk ${ }^{1}$ (1) $\cdot$ Badre El Majid ${ }^{2} \cdot$ Saad Motahhir ${ }^{3}$
}

Received: 6 July 2021 / Accepted: 6 October 2021 / Published online: 8 November 2021

(c) Springer Nature Switzerland AG 2021

\begin{abstract}
The COVID-19 outbreak is a sharp reminder that pandemics, like other rarely occurring catastrophes, have happened in the past and will continue to happen in the future. It is caused by severe acute respiratory syndrome coronavirus 2 (SARSCoV-2), which is an emerging disease. There has been a rapid increase in cases and deaths since it was identified in Wuhan, China. Even if we cannot prevent dangerous viruses from emerging, we should prepare to dampen their effects on society. The current outbreak has had severe economic consequences across the globe, and it does not look like any country will be unaffected. This not only has consequences for the economy; all of society is affected, which has led to dramatic changes in how businesses act and consumers behave. It is in this context that this paper describes a device based on a mechanical spray disinfection system that does not use an electrical source or detection sensor, thus facilitating the use of this system by anyone. The disinfection process is launched automatically by the movement of a door, which changes the position of a piston, triggering the spraying of a disinfectant liquid. This door-controlled automatic decontamination system could be an effective tool in the fight against the current COVID-19 pandemic and, in general, could help to address the health challenges related to hygiene and disease prevention at low cost.
\end{abstract}

Keywords COVID-19 · Disinfectant · Door · Low cost

\section{Introduction}

There are several bacteria and viruses that spread through respiratory droplets from an infected person to other people with whom they have close contact, such as people who live together or provide care. The COVID-19 disease virus is one of them. Indeed, studies show that this virus can survive for several days on surfaces with which we are in daily contact (Ilyas et al. 2020; Shereen et al. 2019). This means that

Responsible Editor: Patrick Da Costa.

Hajar Saikouk

h.saikouk@insa.ueuromed.org

Badre El Majid

badreov@gmail.com

Saad Motahhir

saad.motahhir@usmba.ac.ma

1 INSA, Euromed University of Fes (UEMF), Fez, Morocco

2 Independent Scientist, 11100 Rabat, Morocco

3 ENSA, SMBA University, $30000 \mathrm{Fez}$, Morocco special attention must be paid to areas of daily use (World Health Organization 2022), as well as to areas frequented by different people, such as entrances to houses, bedrooms, changing rooms, sanitary facilities, and hospitals (Spinelli and Pellino 2020). It is in this context, in the fight against the spread of such viruses, that it is particularly important to design a simple device allowing the rapid disinfection of people at each entrance to a multi-use room. This reduces the power of bacteria or viruses to infect, and thus eliminates possible risks of contamination.

Only a few methods that disinfect people at entrances in a mechanical way are reported in the literature. For example, Domingo Callueng (2003) describes a device for disinfecting door handles when triggered by the motion of a hand. Sung-kyu (2017) discloses a device for disinfecting a common entrance to prevent the introduction of fine dust and external germs into a room. A system presented by Xinchang Twilight Automation Equipment Co., Ltd. (2020) is characterized by an automatic household sprayer for whole body disinfection. Yong-jin et al. (2005) reports the invention of a device for the complete disinfection of a person's entire body in order to eliminate various impurities. Joshi (2020) 
describes an idea to develop a disinfectant door to keep a patient suspected of carrying the COVID-19 virus completely isolated from doctors and the medical staff while they collect a COVID-19 test sample. In Kishino et al. (2020), in order to support effective disinfection activities, researchers propose a method that uses a thermographic camera and lightweight background image processing to detect and visualize the parts of a door that have been touched by a person.

State-of-the-art spraying and disinfection equipment for doorways are based on an electrical system consisting of a pump and detection sensors, and a complicated process is used to control these elements. However, some regions do not have sufficient infrastructure to be able to use electrical disinfection systems. A door device that disinfects in a mechanical and automatic way will help any type of person anywhere. Such a design is also easy for medical teams to use. This idea is the basis for the work reported in the present paper.

The rest of this paper is structured as follows. Section 2 presents the design concept for a proposed doorway disinfection device and its operating principle. The challenges involved in developing the innovative disinfection system presented here are described in Sect. 3. Finally, Sect. 4 summarizes the work.

\section{Design concept}

The concept of the proposed device is illustrated in Figs. 1, $2,3,4$, and 5, where the images were generated using the solid modeling computer-aided design program SolidWorks.
The device disinfects people entering through a doorway, as shown in Fig. 1. It includes a pipe surrounding the door frame. This pipe contains small holes with a diameter of less than $5 \mu \mathrm{m}$. The device also includes a tank filled with disinfectant liquid. The spraying pressure is generated inside this tank using a piston manipulated by the movement of the door. When the door is opened, the spraying function is triggered automatically, and the spraying stops when the door returns to its closed state. The system is equipped with a valve to activate or deactivate the automatic spraying process according to the user's needs.

The invention represents a device that completely disinfects a person's body without using an electrical source or a detection sensor. The device has a disinfection system based on a mechanical system composed of four elements: a tank, a piston, a cord that connects the door to the piston rod, and a hose that guides the disinfectant around the door (see Fig. 2).

The reservoir containing the liquid product to be sprayed has a cylindrical shape with two important holes. The first hole makes it possible to introduce the disinfectant liquid and can be closed with a cap. The second hole is linked to an outlet valve at the top of the tank so that the compressed liquid is passed to the pipe (see Fig. 1).

Figure 1 also shows the piston, which consists of two elements and is linked to a rod that compresses the liquid inside the tank. The piston elements are as follows:

- A metal disc that is fixed to the end of the rod and is pierced with a few holes. This disc is heavy and the disinfectant fluid can flow through its holes, and it has the same diameter as the tank.
Fig. 1 Piston and reservoir components

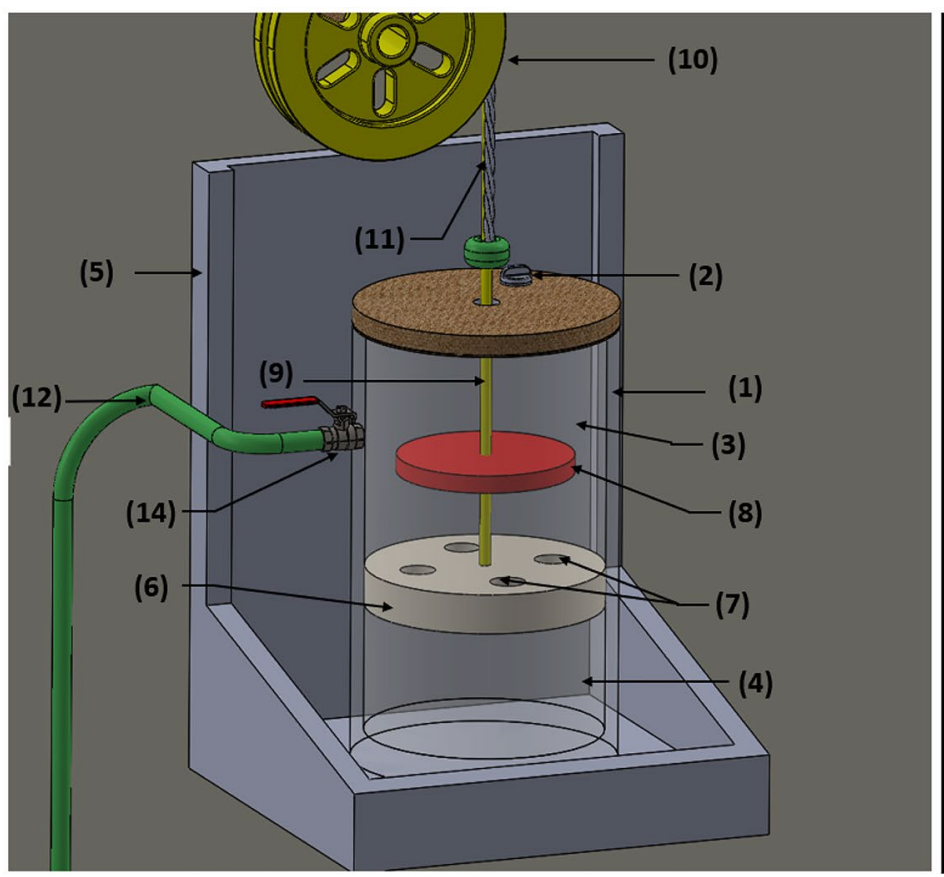

(1) Tank

(1) Cap

(3) Chamber 1

(4) Chamber 2

(5) Tank support

(6) Disc 1

(7) Trous Disque

(8) Disc 2

(9) Rod

(10) Pulley

(11) Rope

(12) Pipe 
Fig. 2 Opened door

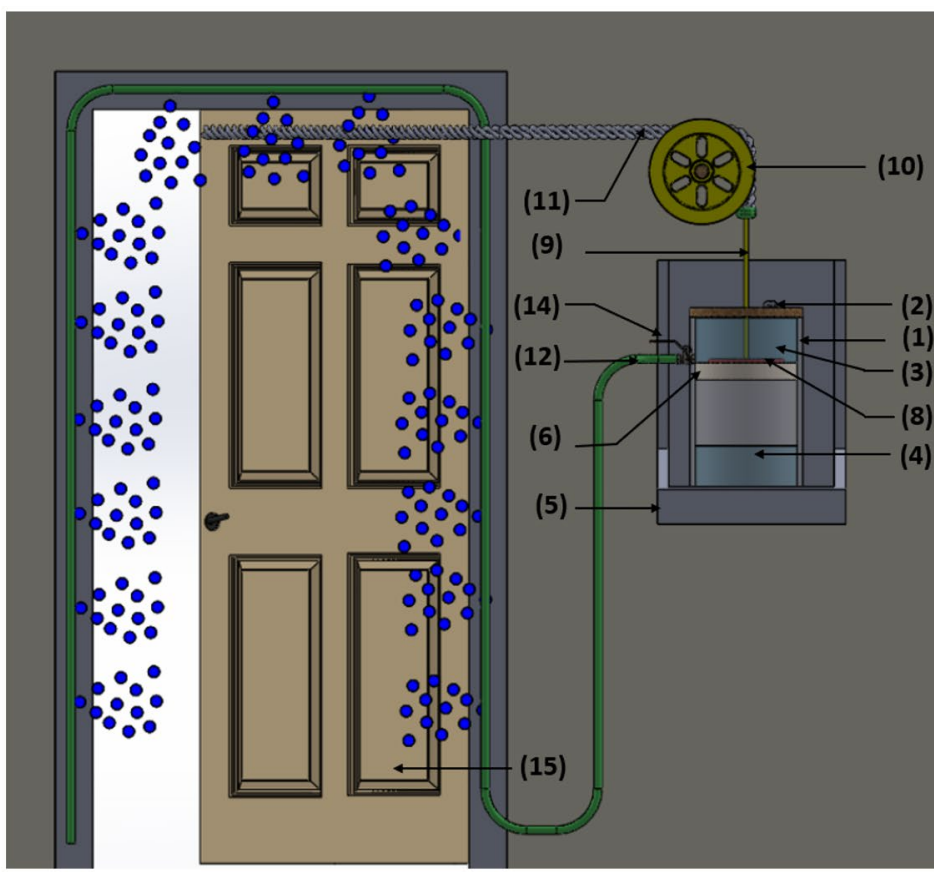
(1) Tank
(1) Cap
(3) Chamber 1
(4) Chamber 2
(5) Tank support
(6) Disc 1
(7) Trous Disque
(8) Disc 2
(9) Rod
(10) Pulley
(11) Rope
(12) Pipe
(13) Pipe holes
(14) Valve
(15) Door

Fig. 3 Compression of the disinfectant liquid in the tank by the piston

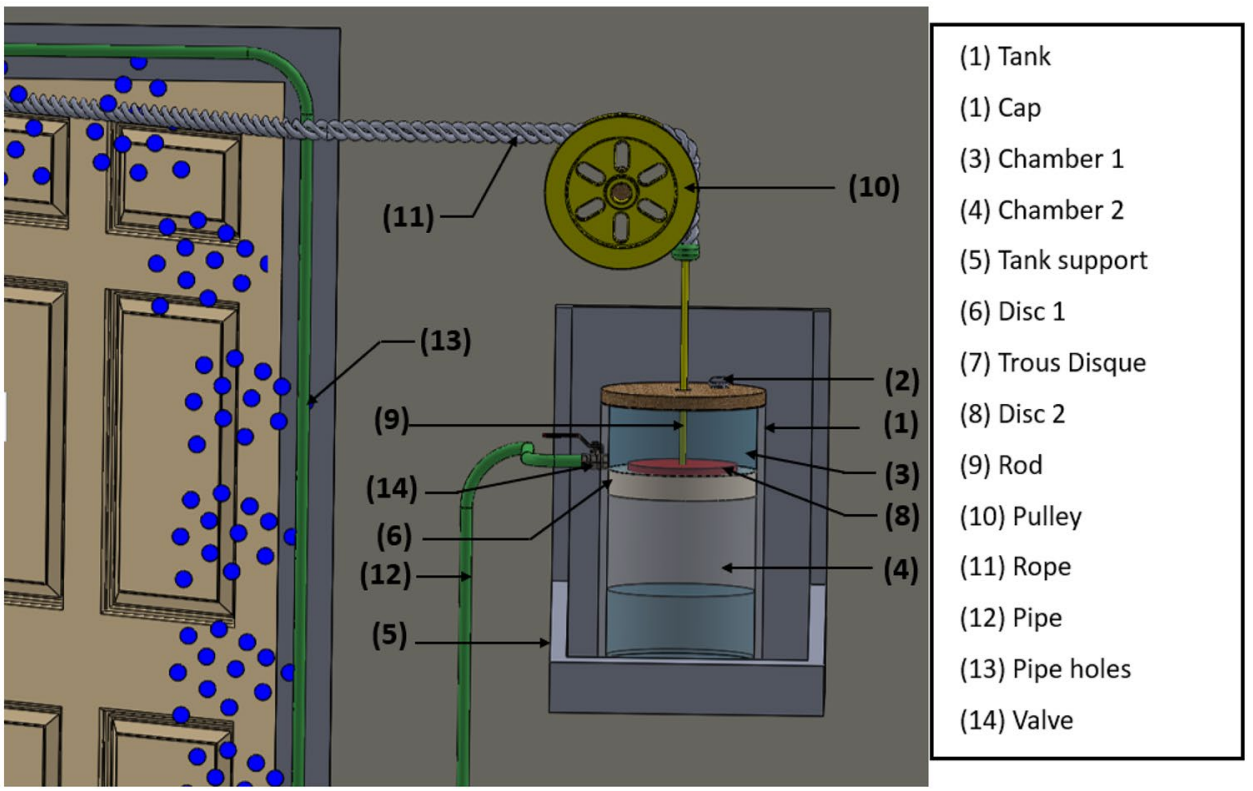

- The second element is a second disc with a diameter smaller than the first disc. It is located above the first disc and is made of light plastic or rubber. However, it does not float on the liquid. Its role is to plug all of the holes in the first disc and thus block the movement of fluid from the first (upper) chamber to the second (lower) chamber of the reservoir through those holes.

Figure 2 shows the location of the rope connecting the door to the piston rod, and which is guided by a pulley fixed to the wall. As shown in Figs. 3 and 4, the pipe guides the disinfectant fluid around the door under pressure from the reservoir, and the fluid exits the pipe through the small holes ( $<5 \mu \mathrm{m}$ diameter) in the pipe in the form of a fog.

Figure 5 shows that when the door is closed, the first disc drops to the bottom of the tank because of its weight, and disinfectant flows from the second chamber through the holes in the disc (see Fig. 5). When the door is opened by a person, a rope that is attached to the end of the door and passes over pulleys pulls the piston rod (and therefore the first disc) upwards. When the first disc makes contact with the second disc, the second disc seals the holes in the first 


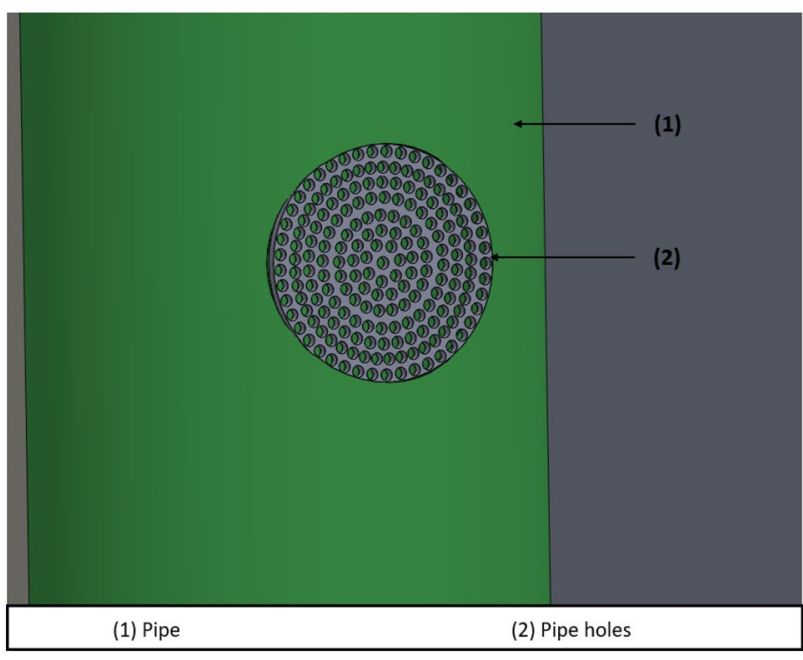

Fig. 4 Holes drilled in the pipe

disc, and the liquid in the first chamber is pressed, which creates a pressure on the liquid in this chamber of the tank. The compressed liquid then passes through the pipe surrounding the door and is sprayed out due to the holes drilled in the pipe.

In this device, no sensor is needed to detect the presence of a person because the opening of the door automatically starts the spraying process. This disinfection system can be activated or deactivated according to the needs of the user using a valve.

\section{Challenges}

Based on promising first research results aimed at developing the concept of the innovative disinfection system presented in this concept paper, work is currently underway to improve various aspects of the system and ensure the safety of people using it. In particular, this work includes:

- Building a mock-up of the disinfecting device

- Testing the spraying/stop function when pressure is generated inside the tank by the movement of the door

- Determining the optimal duration and frequency of disinfection needed to protect the user's skin and meet safety standards

- Comparing existing disinfection systems with our proposal in terms of level of efficiency, cost, and durability

- Keeping costs as low as possible to ensure that the final product will be accessible to low-income countries.

\section{Patent}

The proposed concept is registered as a patent application at Office marocain de la propriété industrielle et commerciale under the following number: MA 49931 (Majid et al. 2020).

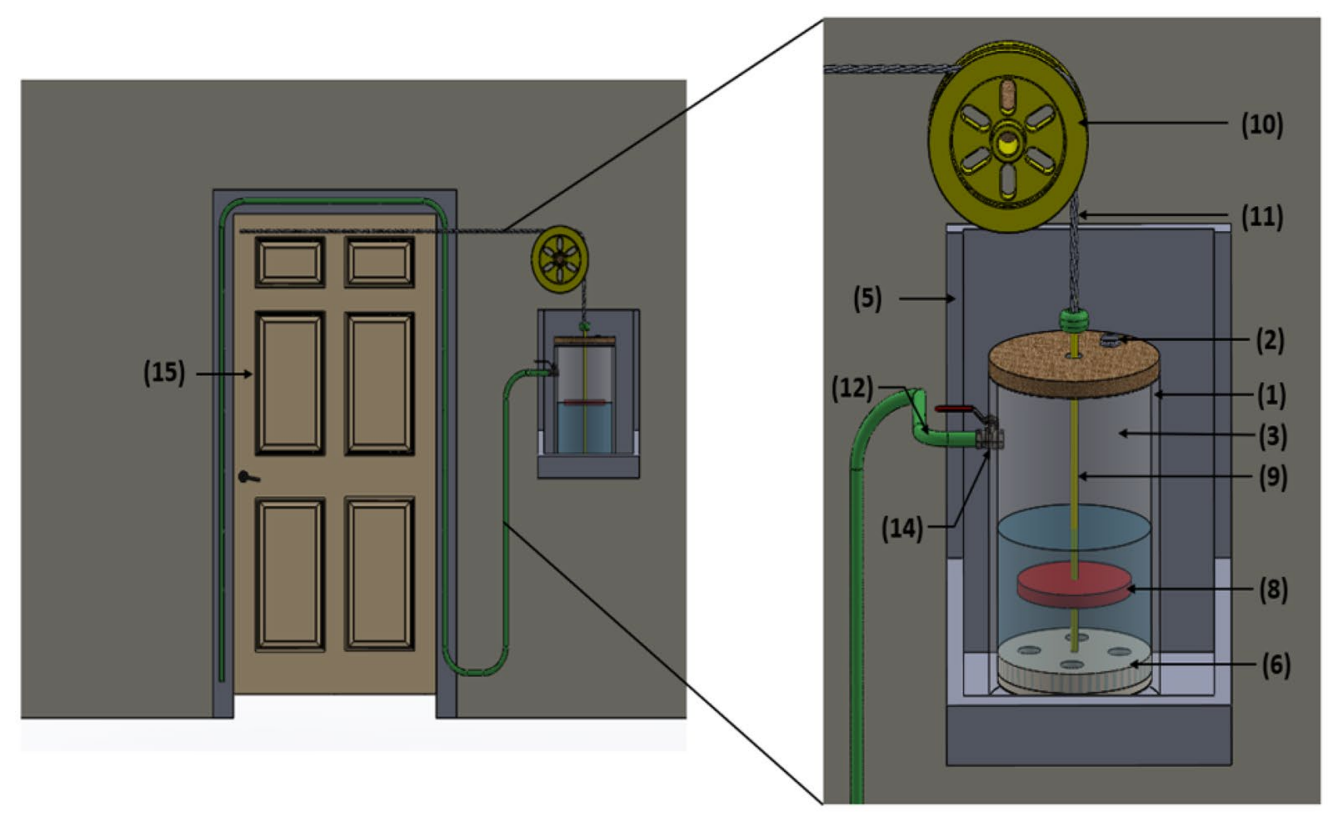
(1) Tank
(1) Cap
(3) Chamber 1
(4) Chamber 2
(5) Tank support
(6) Disc 1
(7) Trous Disque
(8) Disc 2
(9) Rod
(10) Pulley
(11) Rope
(12) Pipe
(13) Pipe holes
(14) Valve
(15) Door

Fig. 5 Closed door 


\section{Conclusions}

Our work opens up an attractive opportunity to develop new solutions for automatic disinfection systems. Our proposal has two major advantages. Firstly, it will allow direct and automatic disinfection of a person entering through a doorway. Secondly, the system represents a low-cost solution that can be used by anyone.

The crisis related to the COVID-19 epidemic has had a significant impact in stimulating the development of innovative solutions. It is important to make this product available as quickly as possible. Our goal is to provide a new, low-cost solution that can effectively contribute to addressing today's sanitary challenge.

\section{References}

Domingo Callueng R (2003) Device for disinfecting door handles. US Patent US6874697B2

El Majid B, Motahhir S, Saikouk H (2020) Dispositif de désinfection par pulvérisation d'un liquide monté sur porte. MA Patent no. 49931. Office marocain de la propriété industrielle et commerciale, Morocco

Ilyas S, Srivastava RR, Kim H (2020) Disinfection technology and strategies for COVID-19 hospital and bio-medical waste management. Sci Total Environ 749:141652
Joshi JR (2020) COVSACK: an innovative portable isolated and safe COVID-19 sample collection kiosk with automatic disinfection. Trans Indian Natl Acad Eng 5:269-275. https://doi.org/10.1007/ s41403-020-00139-1

Kishino Y, Shirai Y, Yanagisawa Y, Ohara K, Mizutani S, Suyama $\mathrm{T}$ (2020) Identifying human contact points on environmental surfaces using heat traces to support disinfect activities: poster abstract. In: ACM (eds) Proceedings of the 18th conference on Embedded Networked Sensor Systems (SenSys '20). Association for Computing Machinery, New York, pp 768-769. https://doi.org/ 10.1145/3384419.3430597

Shereen MA, Khan S, Kazmi A, Bashir N, Siddique R (2020) Disinfection technology of hospital wastes and wastewater: suggestions for disinfection strategy during coronavirus disease 2019 (COVID19) pandemic in China. Environ Pollut 262:114665

Spinelli A, Pellino G (2020) COVID-19 pandemic: perspectives on an unfolding crisis. Br J Surg 107(7):785-787. https://doi.org/ $10.1002 /$ bjs. 11627

Sung-kyu K (2017) Front door cleaning system for preventing inflow of fine dust and virus. KR101973931B1

World Health Organization (2022) Cleaning and disinfection of environmental surfaces in the context of COVID-19. Refrence WHO/2019-nCoV/Disinfection/2020.1. https://www.who.int/ publications/i/item/cleaning-and-disinfection-of-environmentalsurfaces-inthe-context-of-covid-19

Xinchang Twilight Automation Equipment Co., Ltd. (2020) Domestic automatic whole-body disinfection spraying device. CN111150927A

Yong-jin K, Seung-jae B, Jong-wook K, Jae-bong P (2005) A desinfecting system of the person. Korean Patent KR100695034B1 